\title{
Session No: 1526 \\ Advanced Mechatronics: Development of a Course on Modeling and Simulation of Mechatronic Systems
}

\author{
Shuvra Das ${ }^{*}$, Mohan Krishnan ${ }^{+}$, Sandra A. Yost ${ }^{+}$, Kathleen Zimmerman-Oster ${ }^{\perp}$ \\ *Mechanical Engineering Department \\ ${ }^{+}$Electrical \& Computer Engineering Department \\ ${ }^{\perp}$ Psychology Department \\ University of Detroit Mercy \\ Detroit, MI 48219-0900 \\ dass@udmercy.edu
}

\begin{abstract}
Mechatronics refers to the interplay between mechanical and electrical principles that apply to a growing number of industrial products and processes. Despite the importance of this interdisciplinary area, many of today's engineering graduates are unprepared to function competently in environments that require them to integrate electrical and mechanical knowledge areas. In addition, engineers with better communication and teamwork skills are needed to ensure U.S. competitiveness in today's global economy.

In order to address this competency gap a team of faculty members (consisting of faculty from both $\mathrm{ME}$ and $\mathrm{EE}$ departments) started work in the mid-nineties to integrate mechatronics-based activities at all levels of the undergraduate engineering curriculum at University of Detroit Mercy. These included a new senior level technical elective in introductory mechatronics along with mechatronic activities in freshmen design and in the introductory electrical engineering course meant for non-EE majors. This effort has been very successful, and now mechatronics activities are also going on in many pre-college programs that the school runs.

Recently this team received a National Science Foundation grant to take this effort one step further by developing two new advanced courses in the area of modeling and simulation of mechatronic systems and in the area of sensors and actuators, including emerging technologies. One of the key components of this effort is a detailed plan for outcomes assessment. An outcomes assessment expert is also part of the team just as in our earlier efforts. The first of the two courses will be taught for the first time in January 2005. This paper describes in detail the technical content of the planned course as well as the assessment plan for the course.
\end{abstract}

\section{Introduction}

Mechatronics is defined as the synergistic combination of precision mechanical engineering, electronic control, and intelligent software in a systems framework, used in the design of products and manufacturing processes. Design of modern day products involves the knowledge of different engineering disciplines, an ability to communicate well, and work well in multidisciplinary teams. Because engineers are traditionally trained in fields such as either 
Mechanical or Electrical engineering, many of today's engineering graduates are not well prepared to function competently in environments that require them to work on products where electrical and mechanical knowledge areas are intertwined.

An NSF-funded project addresses these competency gaps through the development of two teamoriented, project-based courses as a follow-up to a previously developed "Introduction to Mechatronics" course [1-5]. For this project, we have identified the following goals: (a) to address the need of industrial partners to have engineers educated in the principles and applications of mechatronics, (b) to improve student competencies in communication skills, teamwork, and project management through the increased use of team-oriented, project-based, interdisciplinary approaches to instruction in mechatronics, (c) to increase in engineering students an appreciation for lifelong learning by delivering instruction in mechatronics to this population, and (d) to increase the participation of women and underrepresented minorities in engineering by engaging the freshmen and pre-college populations in hands-on instruction in sensors and actuators.

To achieve these goals, a number of activities are planned. Two new courses in mechatronic system modeling and simulation, and sensors and actuators are being developed and delivered as technical electives for upper-division engineering students. Materials developed for the sensors and actuators course will be adapted for use in hands-on pre-college learning modules. An important feature is a plan for assessing the outcomes of the project. In fact, the project team includes a professional evaluator who will work closely with the co-PIs of the grant, who are from two different engineering disciplines.

\section{Project Goals}

The University of Detroit Mercy (UDM) is uniquely situated to play a major role in mechatronics instruction in the local region. The predominance of the auto industry in the Detroit area, the mandatory cooperative education program, the diversity of our student population, and our ongoing relationships with enthusiastic industry partners are but a few of the factors that position UDM to be a leader in this interdisciplinary area.

(a) Addressing the need of industrial partners to have engineers educated in the principles and applications of mechatronics will be addressed by the development and delivery of two new courses to follow up an Introduction to Mechatronics course that was funded by the CCLI program in 1999. Sensors and actuators are key components in a mechatronic system, and so one of the new courses is dedicated to the study of these components, especially state-of-the-art devices such as smart sensors and micro-electro-mechanical systems (MEMS) devices. A finding from the Introduction to Mechatronics course suggested that skills in the modeling and simulation of mechatronics systems needed to be enhanced in the students served by the course. In the Detroit area, the auto industry and its ancillaries represent the single largest employer base. In recent years, the inclusion of electronics in many vehicle functions has created the demand for engineers who can design systems with integrated mechanical and electrical components. The modern automobile contains a large number of sensors and actuators that are integrated in mechatronic systems found throughout the vehicle. In addition, many producers are showing great interest in virtual prototyping, which requires the ability to derive an accurate

\footnotetext{
"Proceedings of the 2005 American Society for Engineering Education Annual Conference \& Exposition Copyright ASEE 2005, American Society for Engineering Education"
} 
mathematical model of a system, and to create simulations that accurately predict system performance.

(b) Improving student competencies in communication skills, teamwork, and project management has become a critical issue in the preparation of the nation's technical workforce. Through the continuation of team-oriented, project-based, interdisciplinary approaches to instruction in mechatronics, we plan to consciously focus on these skill areas.

(c) Students taking the new courses will come to better appreciate the need for lifelong learning. The modeling and simulation course, for example, will focus on the process of modeling systems rather than on learning the models that already exist for systems. Since new sensors and actuators are being developed on a continuing basis, students will be instructed on how to adapt to the use of newly developed devices.

(d) Increasing the participation of women and underrepresented minorities in engineering by engaging the freshmen and pre-college populations in hands-on instruction in mechatronics will be facilitated by the introduction of mechatronic-based hands-on projects at the freshman and pre-college levels. The authors have already had considerable success in developing and delivering mechatronics modules for use at these levels [6-8]. The development of hands-on modules in the area of sensors and actuators will continue to introduce mechatronics-related topics to tomorrow's engineers. UDM's engineering programs already serve a diverse student population, with a large percentage of students coming from groups that have traditionally been underrepresented in engineering. Furthermore, UDM has a long-standing commitment to urban outreach, and in particular, to urban youth. We believe that the incorporation of industrially relevant and exciting hands-on projects will improve the recruitment and retention of these segments of the population.

\section{Course Content}

Modeling and Simulation of Mechatronic systems will be offered as a technical elective for both mechanical and electrical engineering senior undergraduate students as well as to graduate students. There will be two weekly meetings for an hour and fifteen minutes each. It is expected that students completing this course will be able to:

- implement a structured approach to model mechatronic systems (systems consisting of mixed physical domains).

- develop the governing mathematical equations from the model of the mechatronic system.

- simulate system dynamic behavior for different input conditions.

- interpret simulation results to determine system behavior in physically meaningful terms.

- gain proficiency in the use of appropriate software tools.

- work collaboratively across disciplines and cultures on mechatronics projects.

- demonstrate effective oral and written communication skills in the context of collaborative exercises on mechatronics modeling and simulation.

Student work in this course will consist of homework assignments on the topics covered in class as well as computer projects on simulating mechatronic systems. There will be a mid-term as well as a final exam in the class. The text for the course will be "System Dynamics: Modeling and Simulation of Mechatronic Systems," by Karnopp, Margolis and Rosenberg published by 
John Wiley and Sons [9]. The simulation exercises will be performed on 20-Sim [10], a bond graph based simulation tool, and MATLAB/Simulink [11].

The topics that will be covered are listed below along with some details about each topic:

Introduction to Mechatronic system modeling. Systems, Subsystems, Components.

This topic will consist of introductory comments on what mechatronics is, explained with examples of mechatronic systems such as the copier, automotive engine control, and other systems that the students are already familiar with. This discussion will also emphasize the importance of understanding the multi-disciplinary nature of modern engineering products. In traditional engineering programs we are trained in specific disciplines, such as Mechanical or Electrical Engineering. Since modeling techniques evolved along different paths in different disciplines it is essential to develop a unified approach when dealing with mechatronic products. The importance of such a unified approach will be emphasized during this introductory discussion. This section will conclude with a discussion of systems, subsystems and components through examples of common engineering systems such as simple electrical circuits, springmass-damper systems, etc.

\section{Multiport systems and the concept of bondgraphs}

This section will serve as an introduction to a unified approach to systems modeling: the bond graph technique. This technique is based on energy transfer (as opposed to force or voltage transfer). In this technique components are identified as single, double or triple port elements. The properties and behaviors of these port elements will be discussed in this section. Series and parallel junctions through which these elements transmit energy will also be introduced. The important concepts of power transmission and signal transmission through a system and their impact on the model formulation will be discussed.

\section{Simple mechatronic elements in systems and construction of bondgraphs}

Some of the basic components in all mechatronic systems such as energy storage elements like capacitances and inertances (inertance is a term used for generalized inertia such as mass or inductance) and energy dissipative elements such as resistances and dampers will be discussed. The meaning ofthese components in the mechanical, electrical, hydraulic, and thermal domains will be discussed to emphasize that a few simple basic generalized components can be used to describe multi-disciplinary systems. Two other important elements, the Transformer and Gyrator will also be introduced in this multi-disciplinary context. Sources of effort and flow (e.g. batteries, current sources, force actuators, etc) will be discussed. Mathematical representations of all these components will also be presented as part of this discussion. Using the concepts discussed in the previous and this section, students will be taught to draw bond graph representation of some rudimentary systems such as a RLC circuit and spring mass damper systems. Students will be practicing writing bond graph representations through homework exercises.

\section{Causality and governing equations}

The important concepts of causality and its representation on the bondgraphs will be discussed. Integral and differential causality will be discussed for the different basic elements in the bondgraph. Causality assignment to bonds can be done in an algorithmic fashion and students will also be taught how to assign causality in different bond graph representations and how to

"Proceedings of the 2005 American Society for Engineering Education Annual Conference \& Exposition Copyright ASEE 2005, American Society for Engineering Education" 
resolve conflicts in causality directions. Students will get ample practice through in class and homework exercises. Once causality is determined the governing differential equations for a system can be derived using an algorithmic approach. This approach will be taught to the students and they will practice it in in-class and homework exercises.

System models and computer simulation. Introduction to 20-Sim, a bond graph based system simulator

Equation derivation will continue for mechatronic systems. At this stage the students will be introduced to 20-Sim, a bond-graph based system simulator that automatically derives the equations from a system bondgraph and then can perform system simulation for user-defined component parameters. Mechatronic examples will be assigned for simulation projects at this stage.

Modeling and Analysis of Linear Systems

This section will concentrate on the behavior of linear systems. The concepts of free and forced response and under-, over-, and critically-damped system response will be discussed. Different types of graphical representations of system response will be discussed along with the information that these representations convey. Simulation projects will be assigned.

Modeling Automotive mechatronic systems, motors, drive trains, vehicle dynamics

In this section several actual mechatronic systems from automotive applications will be chosen and dissected, modeled, and simulated, using the bond graph approach. Most of these examples will be chosen from published journal and conference papers and will be somewhat more realistic than text-book type examples.

\section{Control Systems and Transducers}

Control Systems are a critical part of any mechatronic system. Sensor inputs in mechatronic systems are used to initiate control algorithms. Bond graphs deal with exchange of power. To include control loops, signal bonds need to be introduced. In this section, simulation of control loops in mechatronic systems will be taught. This discussion will also comprise of modeling the behavior of transducers (sensors and actuators). The discussions will be followed with simulation assignments in this area.

\section{MATLAB/Simulink software tools}

MATLAB/Simulink is a popular tool used in system modeling. While the bondgraph representation is based on energy flow the MATLAB/Simulink simulation of a system is based on flow of signal. In this section, students will be taught how MATLAB and Simulink can be used to model mechatronic systems. They will be assigned simulation exercises so that they can implement some of the things they learn.

\section{Modeling non-linear systems}

Among the many advanced topics such as modeling non-linear systems, modeling distributed parameter systems, modeling field effects, etc., this has been chosen for discussion in class. One of the classic non-linear problems is the balancing of an inverted pendulum. Problems such as this will be discussed and students will be assigned a small exercise in this area. 


\section{Final Simulation project}

Students will be assigned to pick a mechatronic system from published literature, model and simulate this system, and present the results to the rest of the class. In order to ensure the quality of this work students will be asked to submit a proposal early in the term and will be provided proper feedback so that they are well aware of the scope of their project and can meet the course expectations.

\section{System Examples}

To illustrate the type of systems the students will study and the type of simulation exercises the students will be performing, two examples of mechatronic systems and their models are included here.

\section{Example 1: Permanent magnet DC Motor}

A permanent magnet DC motor is a very commonly used actuator in mechatronic applications (Figure 1). This is used quite often where an electrical input (voltage) is converted into a rotational motion output. For permanent magnet DC motors the torque generated is linearly related to speed of rotation. This makes it an attractive device for use in many applications. PM DC motors can also be quite compact in size and forms the core of other actuators such as servo and stepper motors.

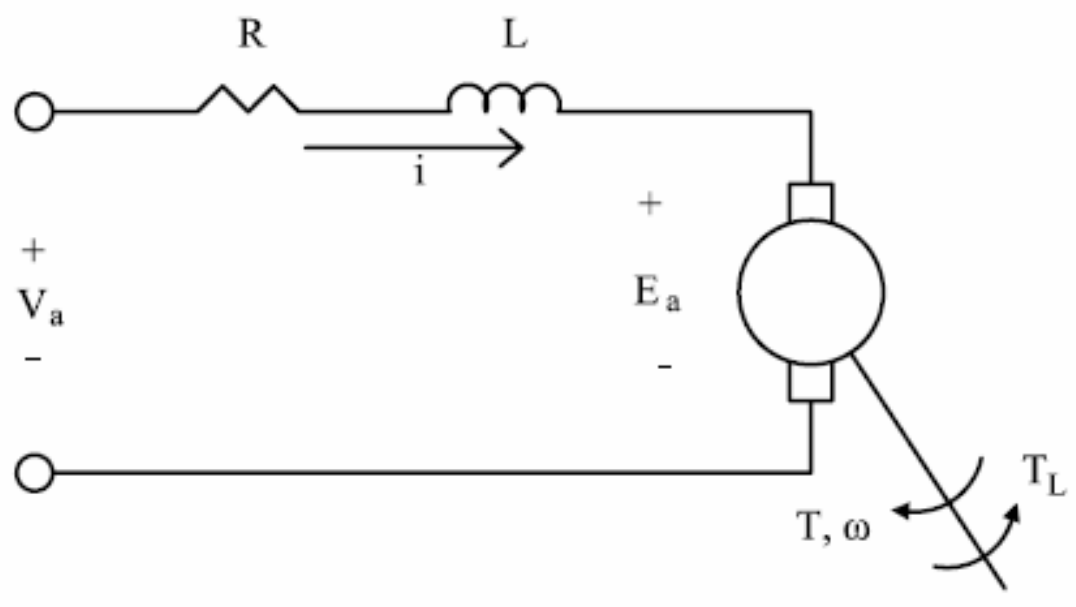

Figure 1: Schematic of a permanent magnet DC motor

The permanent magnet DC motor can be usually modeled as a voltage source that drives a current through an inductor (representing the inductance of the motor winding) and a resistance (winding resistance). The output of the motor is a torque that drives a mechanical inertia load with some damping and elasticity.

The equations that govern motor motions are:

(a) electrical equations

$$
\begin{aligned}
\frac{d i}{d t} & =\frac{1}{L}\left(V_{a}-E_{a}-i R\right) \\
E_{a} & =K_{e} \omega
\end{aligned}
$$


where $L, R$, and $i$ are armature inductance, resistance and current, respectively. $V_{a}$ is the applied voltage, and $E_{a}$ is the back emf that is proportional to the speed of rotation of the armature with $K_{e}$ being the speed constant.

(b) mechanical equations:

$$
\begin{aligned}
& \frac{d \omega}{d t}=\frac{1}{J}\left(T-T_{L}-B \omega\right) \\
& T=K_{t} i
\end{aligned}
$$

where $J$ is the rotor inertia, $\mathrm{T}$ is the motor torque, $T_{L}$ is the load torque, and $B$ is the damping from bearings. Torque generated is directly proportional to the armature current and $K_{t}$ is the motor torque constant.

Figure 2 shows the bondgraph model for the DC motor and the output inertia as drawn in 20SIM. It uses standard terminology such as Se for source of effort, I for inertia or inductance, and $\mathrm{R}$ for resistance (damping or electrical). $\mathrm{GY}$ is used to represent Gyrators, objects that transform effort input into flow output and flow inputs to effort output (such as voltage to speed and current to torque).

In our example the following parameters were used to model the motor.

Motor Resistance $\left(\mathrm{R}_{1}=R=1 \Omega\right)$

Motor Inductance $\left(\mathrm{I}_{1}=L=0.05 \mathrm{H}\right)$

Motor Back-EMF Speed Constant $\left(K_{e}=0.020 \mathrm{~V}-\mathrm{s}\right)$

Motor Force/Torque Constant $\left(K_{t}=0.020 \mathrm{~N}-\mathrm{m} / \mathrm{A}\right)$

Rotational damping coefficient $\left(\mathrm{R}_{2}=\mathrm{B}=0.001 \mathrm{~N}-\mathrm{m}-\mathrm{s} / \mathrm{rad}\right)$

Motor Input Voltage $\left(V_{a}=42.0 \mathrm{~V}\right)$

In our example the rotor inertia is varied at four levels 2.4/1.2/0.6/0.06 $\left(\mathrm{kg} \mathrm{m}^{2}\right)$.

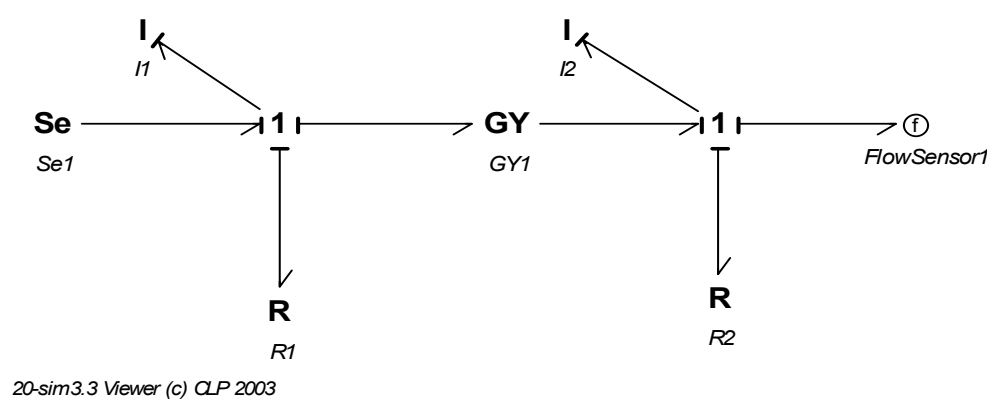

Figure 2: Bondgraph representation of DC motor

Figure 3 shows the output response of the motor model from 20-SIM. As the inertia decreases the response changes from over-damped to under-damped(oscillatory). 
Figure 4 shows the Simulink model for the permanent magnet DC motor. The differential equations listed above are modeled in Simulink with specific blocks that handle mathematical operations such as addition, multiplication, integration, etc. The output of this model is shown in Figure 5. Like the 20-Sim simulation the output shows the system response for different load inertia. Results from the two different software tools indicate that it was possible to model this particular device using both tools.

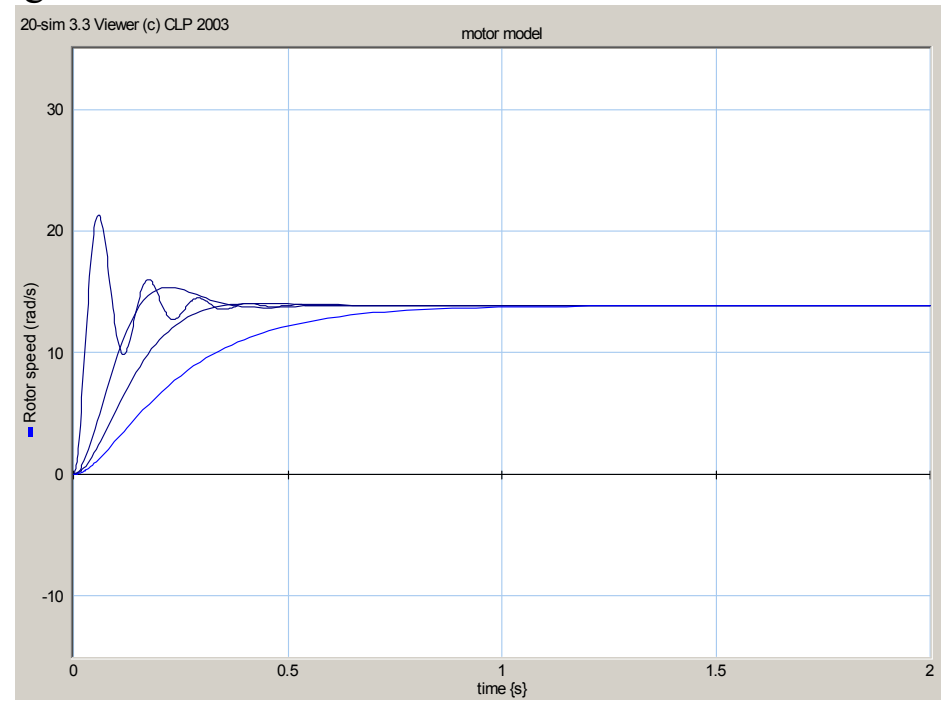

Figure 3: Output from 20-Sim

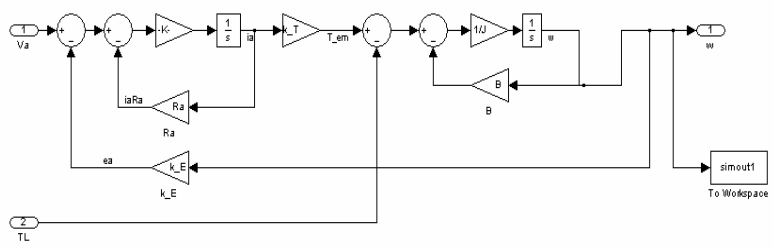

Figure4: Simulink model of DC motor 


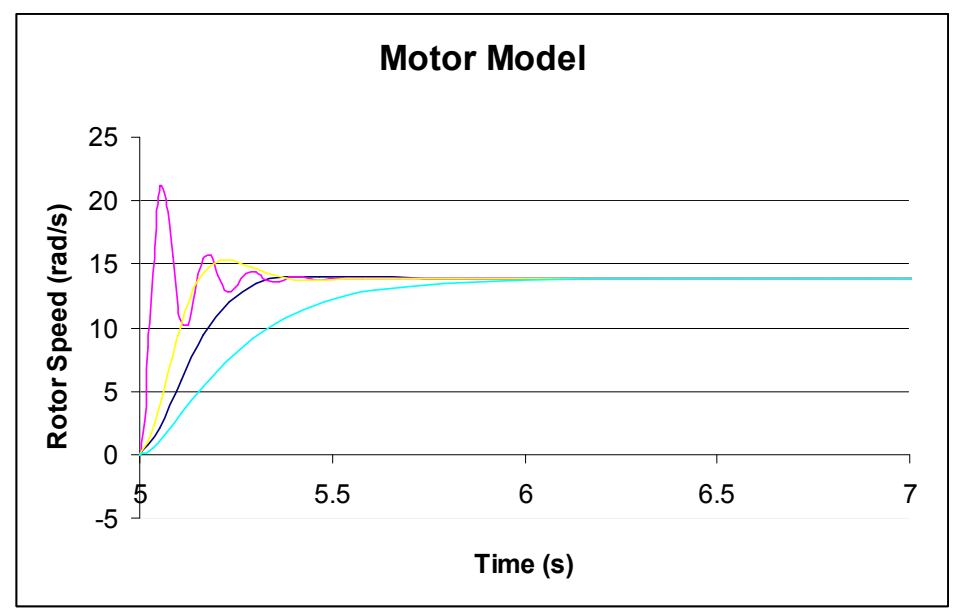

Figure 5: Simulink model output for DC motor

\section{Example 2: Solenoid Actuator [9]}

There is a growing need for Solenoid Actuators with the increase in the number of control applications. Electromechanical solenoids are often used as the main actuator for all types of systems ranging from electrically controlled transmissions to active and semi-active suspensions; they play a major role in the dynamic response of a complete system. Figure 6 shows a schematic of a simple solenoid. This section describes the modeling of a solenoid using simulation and modeling tools SIMULINK and 20-Sim.

The model can be divided into electrical, electromagnetic, and magneto-mechanical components. The electrical model accounts for the flow of current in the coil. If $V_{\text {in }}$ is the voltage input from the driver, $R_{E}$ is the resistance in the coil, $i$ the coil current and $N$ the number of turns of the coil in the housing core, then the rate of change of flux $\dot{\Phi}$ is given by,

$$
\frac{d \Phi}{d t}=\frac{V_{i n}-i R_{E}}{N}
$$

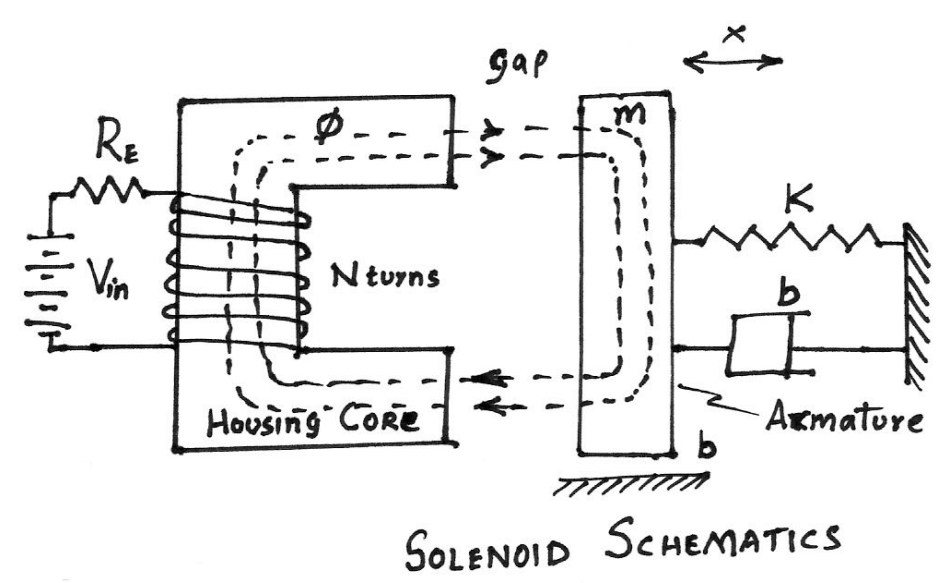

Figure 6: Schematic for solenoid actuator[from 9]

and the magnetomotive force is given by $M=N i$. The magnetomotive force is divided into two components, a portion for the air gap and another one for the iron core. The portion for the air 
gap can be written as $\mathrm{M}_{\text {air }}=\Phi / \mathrm{C}_{\text {air }}$ where $\mathrm{C}_{\text {air }}$ is a constant that is related to the airgap distance, the area of the gap, and the permeability of free space. The portion that pertains to the iron core is in reality a non-linear function of magnetic flux. This is usually obtained from the B-H diagram of the core material and can change based on whether the current is increasing or decreasing because of hysteresis in the B-H diagram. We have made a simplifying assumption for our work and assumed that like $\mathrm{M}_{\text {air }}, \mathrm{M}_{\text {core }}$ is also represented as $\mathrm{M}_{\text {core }}=\Phi / \mathrm{C}_{\text {st }}$, where $\mathrm{C}_{\text {st }}$ is a constant as well. Using these assumptions the flux rate equation can be integrated in the following fashion:

$$
\begin{aligned}
& \frac{d \Phi}{d t}=\frac{1}{N}\left[V_{\text {in }}-\frac{R_{E}}{N}\left(\frac{1}{C_{\text {st }}}-\frac{1}{C_{\text {air }}}\right) \Phi\right] \\
& \frac{d \Phi}{V_{\text {in }}-S \Phi}=\frac{d t}{N}, \quad \text { where } S=\frac{R_{E}}{N}\left(\frac{1}{C_{s t}}-\frac{1}{C_{\text {air }}}\right) \\
& \int_{0}^{\Phi} \frac{d \Phi}{V_{\text {in }}-S \Phi}=\frac{1}{N} \int_{0}^{t} d t \\
& \ln \left(V_{\text {in }}-S \Phi\right)-\ln V_{\text {in }}=-\frac{t}{N} \\
& 1-\frac{S \Phi}{V_{\text {in }}}=e^{-s t / N} \\
& \Phi=\frac{V_{\text {in }}}{S}\left(1-e^{-s t / N}\right)
\end{aligned}
$$

The mechanical force due to the magnetic flux is given as

$$
F=\frac{\Phi^{2}}{2 \times \text { area of gap X permeability }} .
$$

Thus the force can essentially be obtained by squaring the magnetic flux expression.

To model the solenoid with the two software tools the following constants are used as input parameters:

$$
\begin{aligned}
& \text { Spring Stiffness }\left(1 / \mathrm{C}_{2}=\mathrm{K}=40 \mathrm{~N} / \mathrm{m}\right) \\
& \text { Damping Coefficient }\left(\mathrm{R}_{2}=0.001 \mathrm{~N}-\mathrm{s} / \mathrm{m}\right) \\
& \text { Input Voltage }\left(\mathrm{V}_{\mathrm{in}}=12 \mathrm{~V}\right) \\
& \text { Mass of the Armature }(\mathrm{m}=1 / 4 \mathrm{~kg}) \\
& \text { Force Field Applied }\left(\mathrm{F}_{\mathrm{x}}=-\left(\left((24)^{*}(1-\exp (-\mathrm{t} / 40))\right) \wedge 2\right) \mathrm{N}\right) \\
& \mathrm{R}_{1}=\mathrm{R}_{\mathrm{E}}=5 \Omega \\
& \mathrm{GY}=\mathrm{N}=10 \\
& \mathrm{C}_{1}=\mathrm{C}_{\mathrm{st}}=2 \\
& \mathrm{C}_{\mathrm{air}}=2 \\
& 1 / \mathrm{C}_{3}=\mathrm{K}_{\text {stop }}=1600 \mathrm{~N} / \mathrm{m}(\text { when displacement is between } 0 \text { and - } \\
& 1), 0.001(\mathrm{until} \text { the displacement reaches the maximum value })
\end{aligned}
$$


Figure 7 shows the bondgraph model for the solenoid [12]. The model is built with certain basic standard elements such as resistance, source of effort, gyrator, and energy storage devices (capacitors/springs). When the magnet is turned on, the armature mass is drawn towards the magnet until it physically comes in contact with the magnet. At that point no further movement occurs. Physical stoppage of the armature is modeled by adding an extra spring in the model (C3 in the figure), that has very negligible spring constant at the start but the spring becomes extremely stiff when the displacement of the armature reaches the value of 1 unit. The output plot (Figure 8) depicts the distance moved by the actuator. After a total movement of 1 unit (m) the armature comes in contact with the magnet and stops.

Figures 9 and 10 show the Simulink model for the solenoid. Figure 9 shows the main model and Figure 10 is a submodel used in Figure 9 in expanded form. The submodel is used to create the logic for stopping the motion of the armature when it comes in physical contact with the electromagnet. The Simulink model calculates the displacement of the armature by integrating the governing differential equation. The submodel logic forces the model to stop the integration process when the displacement reaches a pre-defined value ( 1 unit in this case), and forces the displacement to remain unchanged at that point.

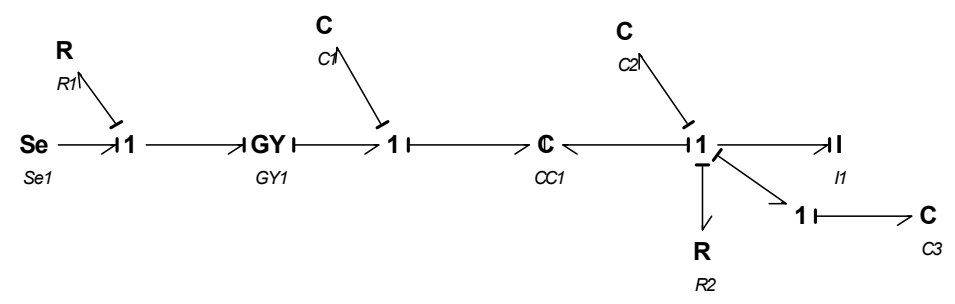

20-sim 3.3 Viewer (c) QP 2003

Figure 7: Bondgraph based model for solenoid

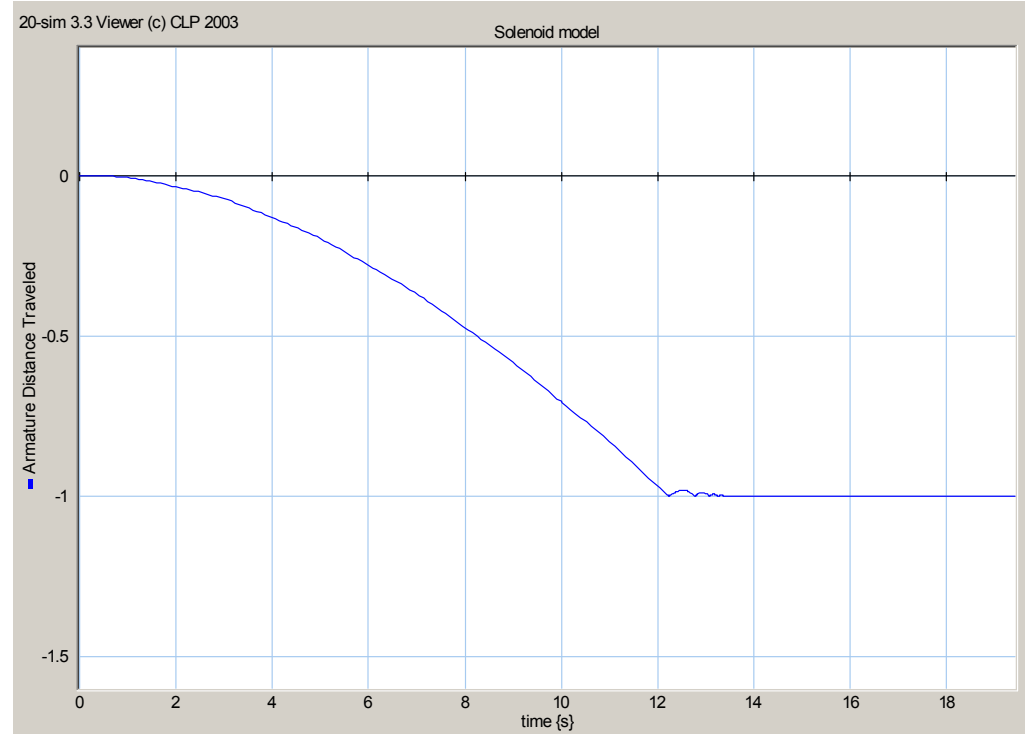

Figure 8: Results from Bondgraph model

"Proceedings of the 2005 American Society for Engineering Education Annual Conference \& Exposition Copyright ASEE 2005, American Society for Engineering Education”, 


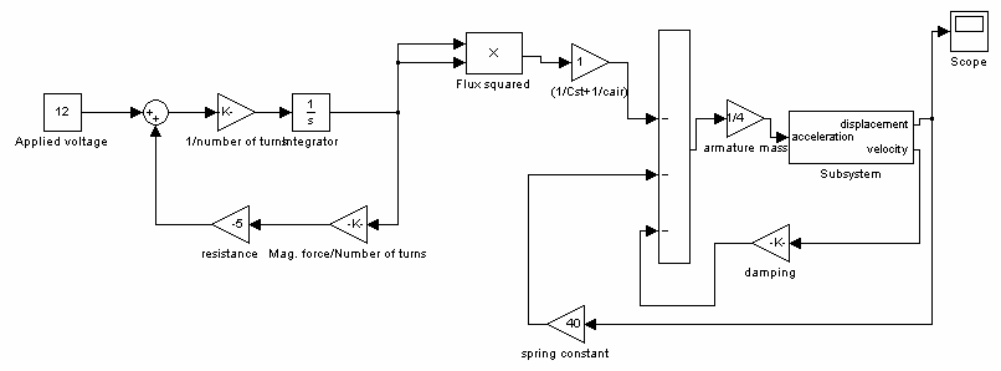

Figure 9: Simulink model of Solenoid valve with subsystem for integration logic

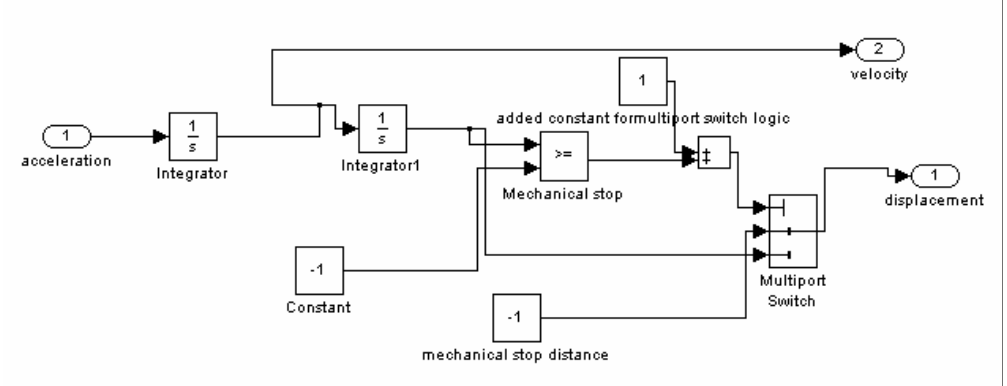

Figure 10: Simulink submodel for the integration logic

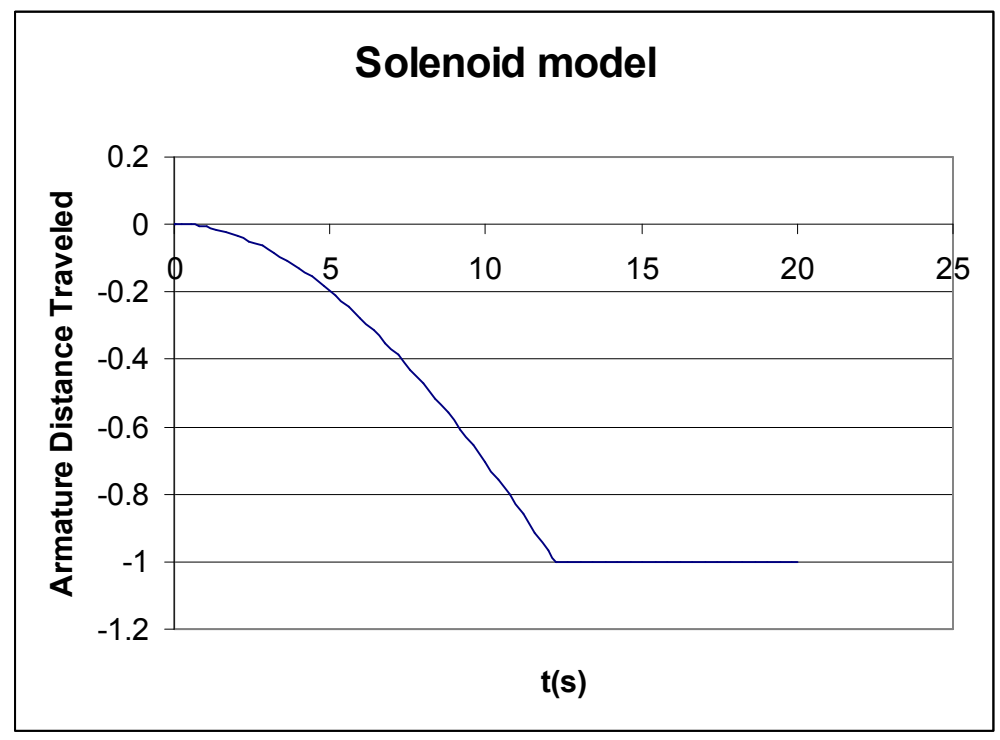

Figure 11: Results from Simulink model

"Proceedings of the 2005 American Society for Engineering Education Annual Conference \& Exposition Copyright ASEE 2005, American Society for Engineering Education" 
Figure 11 shows the displacement of the armature as calculated by the Simulink model. The result is almost identical to that obtained using 20-SIM.

\section{Course Assessment Process}

For this project (and the course) several assessment tools are going to be used. These are preand post-course surveys, a mid-term focus group discussion of the course, an end-of-term focus group discussion of the course, and the assessment expert's evaluation of the final presentation. The pre- and post-course surveys will be conducted on-line. The evaluator will develop the questions on the survey with input from the instructors. The focus groups will be used to obtain qualitative explanation of the quantitative results obtained from the survey. The evaluator will lead the focus group discussions. Table I shows a time line of the assessment process.

Table I: Assessment Plan

\begin{tabular}{|l|l|}
\hline Task & Date \\
\hline $\begin{array}{l}\text { Create Flashlight Pre-Post Survey Tool } \\
\text { And access e-mail accounts of student } \\
\text { Participants }\end{array}$ & December 15, 2004 \\
\hline $\begin{array}{l}\text { Discuss draft survey tool with Grant team } \\
\text { And request members to complete pilot version } \\
\text { On-line }\end{array}$ & December 15, 2004 \\
\hline Revise tool and create flashlight version & January 2, 2005 \\
\hline Access e-mail accounts and send pre-survey & January 10, 2005 \\
\hline $\begin{array}{l}\text { Interpret results and generate written report } \\
\text { Discuss survey results with Grant Team }\end{array}$ & January 30, 2005 \\
\hline $\begin{array}{l}\text { Provide faculty with questions for } \\
\text { mid-term assessment expert led focus group }\end{array}$ & February 28, 2005 \\
\hline $\begin{array}{l}\text { Conduct Observation of Student Presentations } \\
\text { Using a "checklist" to document outcomes } \\
\text { achievement }\end{array}$ & Mid-April \\
\hline $\begin{array}{l}\text { Access e-mail accounts and send post-survey. } \\
\text { Conduct evaluator led focus group to provide } \\
\text { qualitative explanations for pre/post data }\end{array}$ & Late-April \\
\hline
\end{tabular}

At the time of finalizing this paper the pre-course survey was completed and it indicates that $50 \%$ of the students have little or no understanding of Mechatronic Systems, $79 \%$ have little or no experience with Mechatronic Systems, 50\% have little or no experience with Engineering Simulations, and $93 \%$ think they have little or no ability to model a Mechatronic System. Of those surveyed $79 \%$ place a high value on lifelong learning and $50 \%$ of those surveyed feel that they are very likely to use knowledge of Mechtronics in future. 
The survey questions asked and the student responses are shown in table II. These responses will be compared to their performance and their response to similar questions at the conclusion of the course. All the assessment results and its analysis will be presented at the conference.

Table II: Pre-course survey response

\begin{tabular}{|c|c|c|c|c|c|}
\hline \multicolumn{2}{|l|}{ Survey Questions } & $\begin{array}{l}\text { Not } \\
\text { Competent }\end{array}$ & $\begin{array}{l}\text { Little } \\
\text { Competence }\end{array}$ & $\begin{array}{l}\text { Moderate } \\
\text { Competence }\end{array}$ & $\begin{array}{l}\text { Significant } \\
\text { Competence }\end{array}$ \\
\hline \multicolumn{2}{|c|}{$\begin{array}{l}\text { Prior to the start of this course, how well did } \\
\text { you understand mechatronic systems? }\end{array}$} & 1 & 6 & 7 & 0 \\
\hline \multicolumn{2}{|c|}{$\begin{array}{l}\text { How much experience do you have working } \\
\text { with mechatronic systems? }\end{array}$} & 3 & 8 & 3 & 0 \\
\hline \multicolumn{2}{|c|}{$\begin{array}{l}\text { How much experience do you have in } \\
\text { engineering simulation? }\end{array}$} & 2 & 5 & 7 & 0 \\
\hline \multicolumn{2}{|c|}{$\begin{array}{l}\text { How well are you able to model a mechatronic } \\
\text { system? }\end{array}$} & 6 & 7 & 1 & 0 \\
\hline \multicolumn{2}{|c|}{$\begin{array}{l}\text { How much competence do you have with } \\
\text { correlating theoretical/simulation results to } \\
\text { actual systems behavior? }\end{array}$} & 4 & 7 & 3 & 0 \\
\hline \multicolumn{2}{|c|}{$\begin{array}{l}\text { How much competence do you have using } \\
\text { Matlab? }\end{array}$} & 3 & 5 & 5 & 1 \\
\hline \multicolumn{2}{|c|}{$\begin{array}{l}\text { How much competence do you have using } \\
\text { Simulink? }\end{array}$} & 8 & 5 & 0 & 1 \\
\hline \multicolumn{2}{|c|}{$\begin{array}{l}\text { How much competence do you have with bond } \\
\text { graphs? }\end{array}$} & 11 & 3 & 0 & 0 \\
\hline \multicolumn{2}{|c|}{$\begin{array}{l}\text { How much competence do you have working } \\
\text { with people from different cultures? }\end{array}$} & 0 & 1 & 5 & 8 \\
\hline \multicolumn{2}{|c|}{$\begin{array}{l}\text { How much competence do you have working } \\
\text { with people from a different technical major? }\end{array}$} & 2 & 1 & 8 & 3 \\
\hline \multicolumn{2}{|c|}{$\begin{array}{l}\text { How much competence do you have working } \\
\text { with people of the opposite sex? }\end{array}$} & 0 & 0 & 7 & 7 \\
\hline \multicolumn{2}{|c|}{$\begin{array}{l}\text { How much competence do you have making } \\
\text { technical presentations in front of an audience? }\end{array}$} & 1 & 4 & 7 & 2 \\
\hline \multicolumn{2}{|c|}{$\begin{array}{l}\text { How much competence do you have } \\
\text { contributing to a written technical report? }\end{array}$} & 2 & 1 & 7 & 4 \\
\hline & Not Likely & $\begin{array}{l}\text { Somewhat } \\
\text { Likely }\end{array}$ & Very Likely \\
\hline \multicolumn{3}{|c|}{$\begin{array}{l}\text { How likely is it that you will use your knowledge of } \\
\text { mechtronic systems in your future career? }\end{array}$} & 0 & 7 & 7 \\
\hline \multicolumn{3}{|c|}{$\begin{array}{l}\text { How valuable is it for you to continue the educational process } \\
\text { throughout your career (i.e. how much do you value "lifelong } \\
\text { learning")? }\end{array}$} & 0 & 3 & 11 \\
\hline & A & $\mathrm{B}$ & $\mathrm{C}$ & $\mathrm{D}$ & $E$ \\
\hline $\begin{array}{l}\text { How would you grade your writing } \\
\text { skills? }\end{array}$ & 3 & 8 & 2 & 1 & 0 \\
\hline $\begin{array}{l}\text { How would you grade your } \\
\text { presentation skills? }\end{array}$ & 4 & 5 & 5 & 0 & 0 \\
\hline $\begin{array}{l}\text { How would you grade your project } \\
\text { management skills? }\end{array}$ & 4 & 6 & 2 & 2 & 0 \\
\hline $\begin{array}{l}\text { How would you grade your ability to } \\
\text { work as a team member? }\end{array}$ & 8 & 4 & 1 & 1 & 0 \\
\hline
\end{tabular}




\section{Conclusions}

This paper describes one of the two courses that are being developed as part of a NSF funded project. Through these courses we intend to address a competency need that is critical for today's industry. At the time of writing this paper this modeling and simulation course is ready to be taught for the first time. The assessment plan is designed to provide feedback for future improvements of the course. When the paper is presented complete results from the first offering of the course will be available for presentation. It is expected that the successful delivery of these courses will eventually lead to long-term results such as a degree program in Mechatronics.

\section{Acknowledgement}

National Science Foundation award ID 0309719.

\section{References}

1. M. Krishnan, S. Das, S. A. Yost, "Team-Oriented, Project-Based Instruction in a New Mechatronics Course," IEEE/ASEE Frontiers in Education Conference (FIE'99), San Juan, Puerto Rico, Nov. 1999, pp. 13d4/1-13d4/6.

2. S. Das, S. A. Yost, M. Krishnan, "Effective Use of Web-Based Communication Tools in a Team -Oriented, Project-Based, Multidisciplinary Course," IEEE/ASEE Frontiers in Education Conference (FIE'99), San Juan, Puerto Rico, Nov. 1999, pp.13a2/14-13a2/17.

3. S. A. Yost, M. Krishnan, S. Das, "Mechatronics: A Comprehensive, Interdisciplinary Curriculum Development Initiative," IEEE/ASEE Frontiers in Education Conference (FIE'99), San Juan, Puerto Rico, Nov. 1999, pp. 13a1/1-13a1/1.

4. L. Carlson, S. A. Yost, M. Krishnan, S.Das, "Outcomes-Based Assessment for Comprehensive Curriculum Development in Mechatronics," IEEE/ASEE Frontiers in Education Conference (FIE'00), Kansas City, Mo, Oct 19-21, 2000, pp. t4a/1-t4a/5.

5. S.Das, M. Krishnan, S. A. Yost, "Mechatronics: A Comprehensive Interdisciplinary Curriculum Development Initiative," NSF Showcase presentation at the IEEE/ASEE Frontiers in Education Conference (FIE'00), Kansas City, Mo, Oct 19-21, 2000 (poster only).

6. S. A. Yost, D. Maggio, "The Mechatronics Road Show: Building on Success in Mechatronics Curriculum Development," ASEE 2004 Conference Proceedings.

7. S. A. Yost, "Taking Mechatronics on the Road," Proceedings, 2002 SWE National Conference, Detroit, MI, October 2002.

8. S. A. Yost, "Introducing Mechatronics in a First-Year Intro to Engineering Design Course," ASEE 2000 Conference Proceedings, St. Louis, MO, June 2000.

9. Karnopp, Margolis and Rosenberg, "System Dynamics: Modeling and Simulation of Mechatronic Systems", John Wiley, 2000. 
10. Mathworks Inc., http://www.mathworks.com/, Natick, MA.

11. 20-sim, http://www.20sim.com/product/history.html, University of Twente, Enschede, Netherlands.

12. D.Hrovat, J.Agsari and M.Fodor, "Automotive Mechatronic Systems" Mechatronic Systems Techniques and Applications, C.T. Leondes (ed.), vol.2, Gordon and Breach Science publishers, Amsterdam, 2000, pp.1 - 98. 